Article

\title{
Influence of Temperature on the Mechanical Properties and Reactive Behavior of Al-PTFE under Quasi-Static Compression
}

\author{
Huai-Xi Wang ${ }^{1}$, Xiang Fang ${ }^{1, *}$, Bin Feng ${ }^{2}$, Zhen-Ru Gao ${ }^{1}$, Shuang-Zhang $\mathrm{Wu}^{1}$ and \\ Yu-Chun Li ${ }^{1, *}$ \\ 1 College of Field Engineering, PLA Army Engineering University, Nanjing 210007, China; \\ 15251853685@163.com (H.-X.W.); gygzr@sina.com (Z.-R.G.); shsnake@163.com (S.-Z.W.) \\ 2 China Huayin Ordnance Test Center, Huayin 714200, China; fengbinplaust@gmail.com \\ * Correspondence: fangxiangjs@163.com (X.F.); 13851838131@163.com (Y.-C.L.); \\ Tel.: +86-138-0904-4811 (X.F.); +86-138-5183-8131 (Y.-C.L.)
}

Received: 1 December 2017; Accepted: 5 January 2018; Published: 10 January 2018

\begin{abstract}
Al-PTFE (aluminum-polytetrafluoroethylene) is a typical kind of Reactive Material (RM), which has a variety of potential applications in weapon systems. In this paper, quasi-static compression experiments were carried out for a pressed and sintered mixture of Al and PTFE powders using a microcomputer-controlled electronic universal testing machine. The results show that both the mechanical property and reactive behavior of Al-PTFE are strongly temperature-dependent. The material undergoes a brittle-ductile transition associated with a temperature-induced crystalline phase transformation of the PTFE matrix. At low temperatures $\left(-18,0\right.$, and $\left.16{ }^{\circ} \mathrm{C}\right)$, samples of Al-PTFE failed with shear crack and no reaction was observed. As the temperature increased $\left(22,35\right.$, and $\left.80^{\circ} \mathrm{C}\right)$, Al-PTFE exhibited a high toughness and violent reaction occurred in all of the tested samples. Scanning electron microscope observations showed different fracture mechanisms of the PTFE matrix and the increase in toughness was due to the formation of PTFE fibrils which could dissipate energy and bridge crack plane during plastic deformation.
\end{abstract}

Keywords: Al-PTFE; quasi-static compression; mechanical response; reactive behavior; temperature

\section{Introduction}

Reactive Material (RM), which consists of at least two non-explosive solid components, can release a great amount of energy and make effective damage upon impacting with targets. Al-PTFE (aluminum-polytetrafluoroethylene) is regarded as a typical kind of RM, for which the synthesis process was first reported by Joshi [1]. When the composite of Al-PTFE is mixed at the stoichiometric ratio of 26.5:73.5 by weight, the theoretical energy released could reach up to $8.68 \mathrm{~kJ} / \mathrm{g}$ [2]. Due to its high energy density, Al-PTFE has received much attention in the past decades.

To ensure its safety and reliability in the process of manufacture and application, it is important to have a thorough understanding of the mechanical response of Al-PTFE under different conditions. Raftenberg et al. [3] carried out quasi-static compression tests and high-rate split Hopkinson bar experiments for Al-PTFE. The data measured were used to determine the parameters for the Johnson-Cook model and the consistency was examined between the simulation and experiment in terms of specimen shape versus time. Ge et al. [4] studied the mechanical behavior of Al-PTFE with a numerical method at the microscale. The models were based on real microstructures of Al-PTFE and the microstructural parameters, such as the geometry, distribution, and sizes of Al particles, were taken into account. Cai et al. [5] found that the addition of $W$ could effectively improve the strength of Al-PTFE. Subsequently, Xu et al. [6], Zhang et al. [7], Wang et al. [8], and Ge et al. [9] investigated 
the mechanical behavior of Al-W-PTFE by differing the W content and particle size. Although the influencing factors on the mechanical property of Al-PTFE have been extensively studied in the literature listed above, very little attention has been paid to the effect of temperature.

Generally, Al-PTFE is thought to be inert under quasi-static compression. However, Feng et al. [10] reported a reaction phenomenon of Al-PTFE samples after a specific heat treatment procedure under quasi-static loading. Micrographs and finite element simulation of the sample in the critical initiation state suggested that the reaction was more like a mechanochemical process rather than a thermochemical one. In the following study [11], they investigated the influence of sintering temperature, equivalence ratio, and $\mathrm{Al}$ particle size on the reaction phenomenon under quasi-static compression and a crack-induced initiation mechanism was proposed, while the effect of temperature was not taken into account either.

PTFE is a kind of semi-crystalline polymer in nature. The crystalline material is embedded in the amorphous regions and the crystalline regions are interconnected by amorphous chains [12]. The melting point (the first-order transition from a partly crystalline to a completely amorphous structure) is about $330{ }^{\circ} \mathrm{C}$, which is much higher than that of the corresponding hydrocarbon polymer [13]. The glass transitions in the amorphous regions of PTFE are located at -97 and $127^{\circ} \mathrm{C}$ [14-16], both of which are second-order transitions. In the crystalline regions there are four distinct crystalline phases depending on pressure and temperature $[17,18]$, which are shown in Figure 1. The figure is plotted for illustrative purposes only and the pressure dependencies are not exactly correct. As can be seen from Figure 1, PTFE exhibits three crystalline phases at ambient pressure. The first crystalline phase transition between phases II and IV happens at $19^{\circ} \mathrm{C}$, which is an unraveling in the helical conformation from a well-ordered triclinic structure with 13 atoms $/ 180^{\circ}$ turn [19] to a partially ordered hexagonal structure with 15 atoms $/ 180^{\circ}$ turn [20]. Further rotational disordering and untwisting of the helices occurs at $30{ }^{\circ} \mathrm{C}$, giving way to phase I to form a pseudohexagonal structure [21]. The first-order transitions between crystalline phases of PTFE are reversible and unique among polymers [13], and the temperatures that Al-PTFE is likely to encounter in application cover the two phase transition temperatures, so it is essential to develop an understanding of the effects of temperature-induced phase transitions on the properties of Al-PTFE over the normal range of operating temperatures.

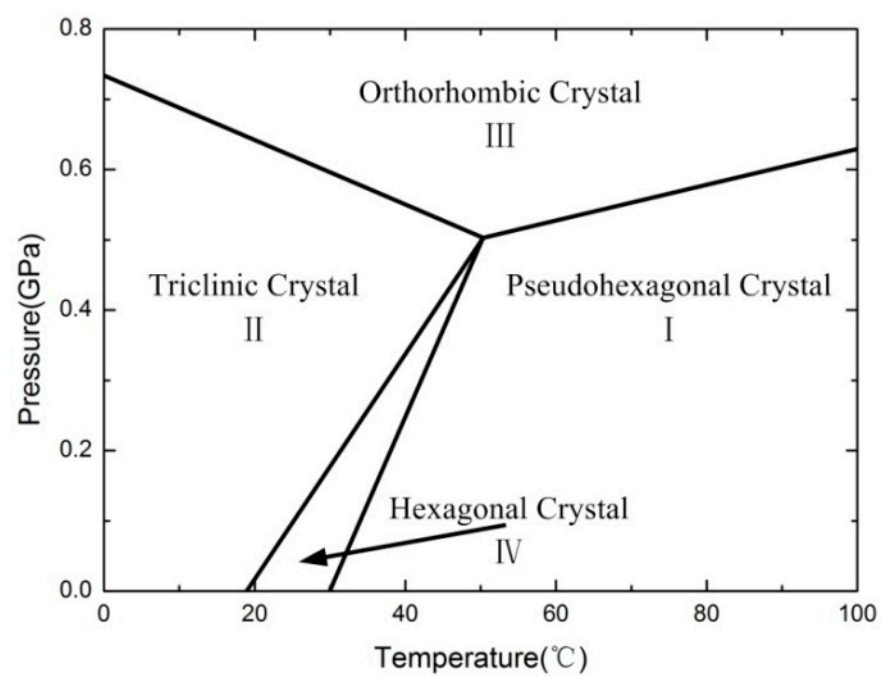

Figure 1. Crystalline phases of PTFE (polytetrafluoroethylene) as a function of temperature and pressure.

In this paper, the mechanical properties and reactive behavior of Al-PTFE under quasi-static compression were investigated at temperatures between -18 and $80{ }^{\circ} \mathrm{C}$, which were chosen to encompass the three crystalline phases of PTFE with transitions at 19 and $30^{\circ} \mathrm{C}$. The results are 
presented and described in detail, and the relationship between mechanical property and reaction phenomenon of Al-PTFE is built.

\section{Materials and Experiments}

\subsection{Sample Preparation}

$\mathrm{Al}$ (purity 99.5\%, average particle size $1 \mu \mathrm{m}$, from Jin Tian, Luxi County, Hunan, China) and PTFE (purity 99\%, average particle size $25 \mu \mathrm{m}$, from 3M, Shanghai, China) were mixed at the stoichiometric ratio of 26.5:73.5 by weight. The preparation process was based on the patent of Nielson et al. [22], which is shown in Figure 2, along with the main steps described below.

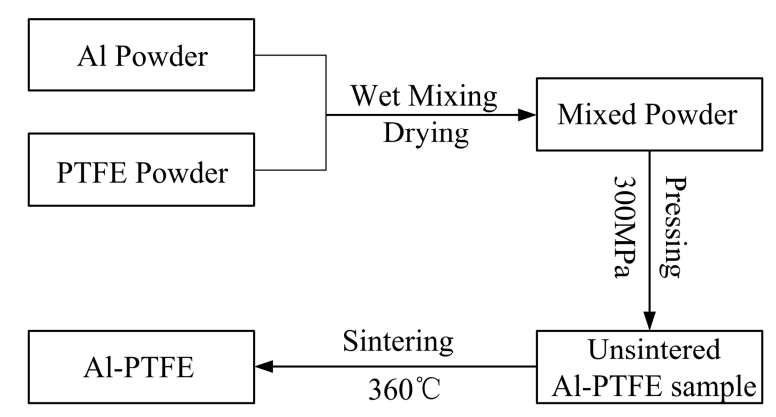

Figure 2. The preparation process of Al-PTFE samples.

Firstly, $\mathrm{Al}$ and PTFE powders were put into a beaker containing ethanol solution, and stirred by an electric blender for at least $20 \mathrm{~min}$ to ensure a thorough mixing. Then the mixed solution was dried at $60^{\circ} \mathrm{C}$ for $48 \mathrm{~h}$, to make the ethanol fully evaporate. Secondly, the dried mixture was pressed into samples with a size of $\varnothing 10 \mathrm{~mm} \times 10 \mathrm{~mm}$ for quasi-static compression tests under a pressure of $300 \mathrm{MPa}$. To prevent the rebound of the sample, the pressure was held for a minimum of $1 \mathrm{~min}$. Finally, the pressed samples were sintered in a vacuum oven. The oven was heated to the sintering temperature of $360^{\circ} \mathrm{C}$ at a heating rate of $90^{\circ} \mathrm{C} / \mathrm{h}$. Samples were soaked in the sintering temperature for $4 \mathrm{~h}$ and cooled to room temperature at a cooling rate of $50^{\circ} \mathrm{C} / \mathrm{h}$. The sintering process was realized by a programmable temperature controller embedded in the oven. The samples after sintering are shown in Figure 3.

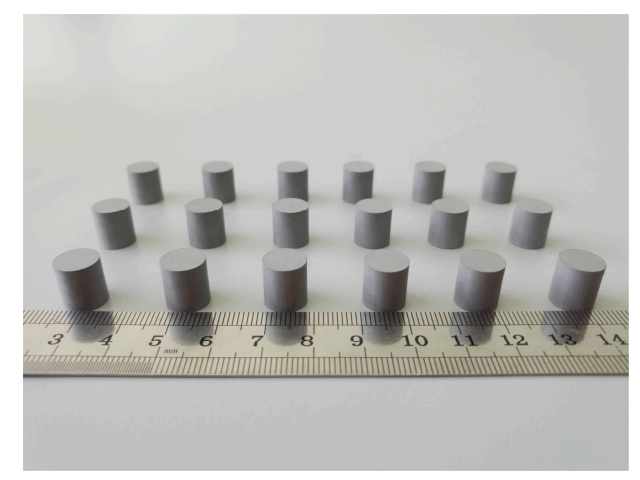

Figure 3. Samples of Al-PTFE for quasi-static compression tests.

In order to examine the homogeneity of prepared material, a Hitachi S-4800 scanning electron microscope (SEM), from HITACHI, Tokyo, Japan, was used to observe the interior of the sample (Figure 4). The microvoids in Figure 4a were formed by Al particles, which were on the opposite side of the observation area. It is obvious that $\mathrm{Al}$ particles are uniformly distributed in PTFE matrix. 
The distributions of $\mathrm{Al}, \mathrm{C}$, and $\mathrm{F}$ (Figure $4 \mathrm{~b}-\mathrm{d}$ ) further indicate that the $\mathrm{Al}$ and PTFE powders were homogeneously mixed through the preparation process outlined in this paper.

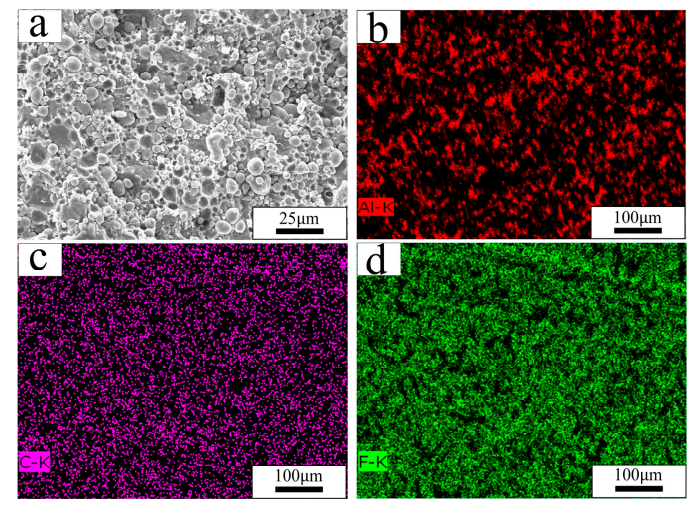

Figure 4. Internal SEM image and element distributions of the Al-PTFE sample: (a) SEM image; (b) Al element; (c) C element; (d) F element.

\subsection{Quasi-Static Compression Tests}

Quasi-static compression tests were carried out by a CMT5105 microcomputer-controlled electronic universal testing machine (MTS industry system (Chinese) Co. Ltd., Shenzhen, Guangdong, China) with a loading capacity of $100 \mathrm{kN}$, and the standard used was GB/T 1041-2008 (Plastics-Determination of compressive properties). The load was applied at a speed of $60 \mathrm{~mm} / \mathrm{min}$, corresponding to the nominal strain rate of $0.1 / \mathrm{s}$. A digital video camera with a frame frequency of $40 \mathrm{~Hz}$ was used to record the reaction phenomenon that occurred in the compression process. Prior to the tests, samples were soaked at desired test temperature for at least $2 \mathrm{~h}$ to ensure thermal equilibrium. Due to the friction on contact surfaces, the ends of samples were retarded from moving outward during deformation. Therefore, petroleum jelly was used to lubricate both ends of the sample to alleviate the friction. Three samples were tested at each temperature to examine the reproducibility of experimental results.

According to the data collected by the testing machine, the engineering stress and engineering strain could be calculated by the following equations:

$$
\left\{\begin{array}{l}
\sigma_{e}=\frac{P}{A_{0}} \\
\varepsilon_{e}=\frac{h_{0}-h}{h_{0}}
\end{array}\right.
$$

where $\sigma_{e}$ and $\varepsilon_{e}$ are the engineering stress and engineering strain, respectively. $P$ is the applied load and $h$ is the instantaneous height of the sample during the compression test. $A_{0}$ and $h_{0}$ are the initial cross-sectional area and height of the sample, respectively. Based on the assumption of a constant sample volume during deformation, the true stress and true strain could be expressed as:

$$
\left\{\begin{array}{l}
\sigma_{t}=\frac{P}{A}=\frac{P}{A_{0}}\left(1-\varepsilon_{e}\right) \\
\varepsilon_{t}=\ln \frac{h}{h_{0}}=\ln \frac{1}{1-\varepsilon_{e}}
\end{array}\right.
$$

where $\sigma_{t}$ and $\varepsilon_{t}$ are the true stress and true strain, respectively. $A$ is the instantaneous cross-sectional area of the sample.

\section{Results and Discussion}

\subsection{Mechanical Response}

Three samples were tested under identical conditions at each temperature and excellent reproducibility between samples was achieved. Taking the experimental results of samples at $35^{\circ} \mathrm{C}$ 
as an example, the stress-strain curves of the three Al-PTFE samples almost overlapped together (Figure 5), which provided confidence that the data obtained in this paper are reliable.

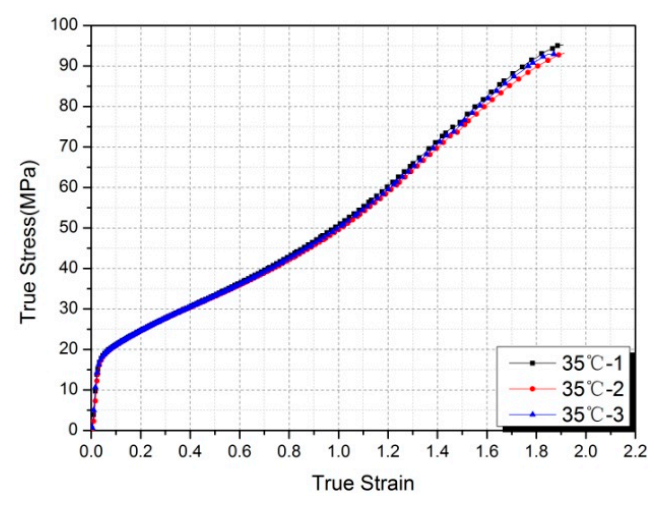

Figure 5. True stress-strain curves of three Al-PTFE samples tested at $35^{\circ} \mathrm{C}$.

The true stress-strain curves of Al-PTFE samples tested at different temperatures are shown in Figure 6 . The results presented are the average of three tests at each temperature and the standard deviation is less than 1.6 MPa. As expected, the mechanical response showed significant temperature dependence. At low temperatures $\left(-18,0\right.$, and $\left.16^{\circ} \mathrm{C}\right)$, a stress-drop phenomenon was observed before the failure of samples, which was not manifested at high temperatures $\left(22,35\right.$, and $\left.80^{\circ} \mathrm{C}\right)$.

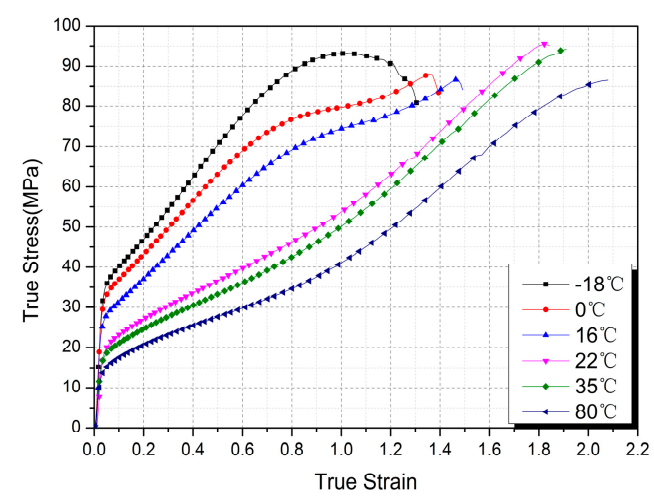

Figure 6. True stress-strain curves of Al-PTFE samples tested at different temperatures.

As can be seen from Figure 7, Al-PTFE underwent a gradual transition from brittleness to ductility with increased temperature. The yield stress and true failure strain of samples were strongly temperature-dependent. This was reflected by a $57 \%$ decrease of yield stress from $35.43 \mathrm{MPa}$ at $-18{ }^{\circ} \mathrm{C}$ to $15.17 \mathrm{MPa}$ at $80{ }^{\circ} \mathrm{C}$, and a $59 \%$ increase of true failure strain from 1.31 to 2.08 over the same temperature range. Besides, a very unusual change was observed between 16 and $22{ }^{\circ} \mathrm{C}$. Both of the mechanical parameters of Al-PTFE exhibited bilinear temperature dependence, with a high slope below $16{ }^{\circ} \mathrm{C}$ and a low slope above $22^{\circ} \mathrm{C}$. In addition to the reduction in yield stress with increased temperature, a similar temperature dependence was also observed in flow stress during plastic deformation. Figure 8 showed the curves of flow stress vs. temperature at different true strains, which are almost identical with the curve of yield stress vs. temperature. At the same true strains, the flow stress of Al-PTFE dropped dramatically at low temperatures (below $16^{\circ} \mathrm{C}$ ) and then to a lesser degree after an unusual change (between 16 and $22{ }^{\circ} \mathrm{C}$ ). 


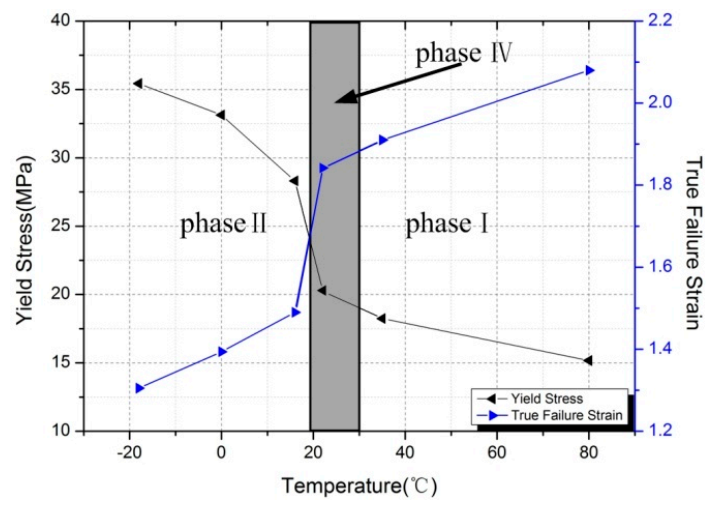

Figure 7. The yield stress and true failure strain of samples as a function of temperature.

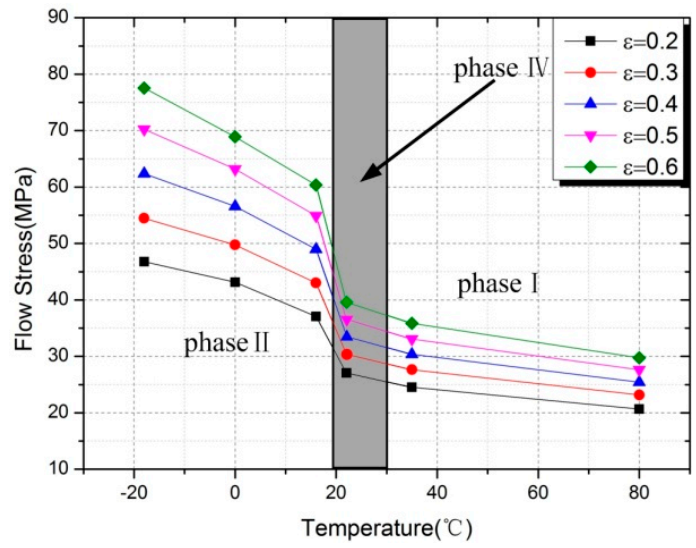

Figure 8. The flow stress at different strains as a function of temperature.

Similar relationships between mechanical properties of PTFE and temperatures were reported in previous studies. Speerschneider and Li [23] found that PTFE showed a crystalline size effect and stress drop phenomenon in its flow-stress relations at low temperatures. Brown et al. [24] found that PTFE underwent transitions from brittle-fracture below $19{ }^{\circ} \mathrm{C}$ to ductile fracture with large-scale plasticity over $30{ }^{\circ} \mathrm{C}$ associated with crystalline phase transformations in tensile tests. Rae et al. $[25,26]$ investigated the properties of PTFE in compression and tension. The results showed that the mechanical properties were strongly affected by strain-rate and temperature. Moreover, the temperature dependence of the Young's modulus and yield stress both appeared to be bimodal, with a steeper slope below temperature for PTFE in phase II and a second shallower slope above temperature for PTFE in phase I. The research works mentioned above demonstrated that the mechanical properties of Al-PTFE were dominated by PTFE matrix.

\subsection{Fractography}

Because of the complete reaction of Al-PTFE samples at high temperatures (the reaction phenomenon was discussed in detail in Section 3.3), there were no samples left after tests and the fracture mechanism could not be analyzed. To further understand the dependence of mechanical response on temperature, PTFE samples were prepared and compressed under identical conditions and the fracture surfaces of recovered samples were characterized with SEM. Areas of interests were coated with gold to promote electrical conductivity.

The macroscopic deformation of PTFE at different test temperatures differed markedly (Figures 9a, 10a and 11a), and a brittle-ductile transition was observed. PTFE in phase II, as represented at $-18{ }^{\circ} \mathrm{C}$ in Figure 8, exhibited a brittle fracture morphology with a smooth surface (Figure 9c). Fracture propagated radially through the sample, as indicated by linear river markings in Figure $9 \mathrm{~b}$. 
Microvoids were observed on the fracture surface under higher magnification (Figure 9d). Completely different from PTFE in phase II, PTFE in phase IV, as represented at $22^{\circ} \mathrm{C}$ in Figure 10, fractured with a high failure strain. The SEM micrographs revealed a rough fracture surface (Figure 10b) and the formation of PTFE fibrils was observed (Figure 10c). The diameter of fibers was as small as $\sim 100 \mathrm{~nm}$. In this sense, they could be termed nanofibrils. Similar to PTFE in phase IV, PTFE in phase I, as represented at $35^{\circ} \mathrm{C}$ in Figure 11, exhibited substantial plastic deformation. PTFE fibers could also be seen in Figure $11 \mathrm{~b}, \mathrm{c}$, in which they became longer and thicker.
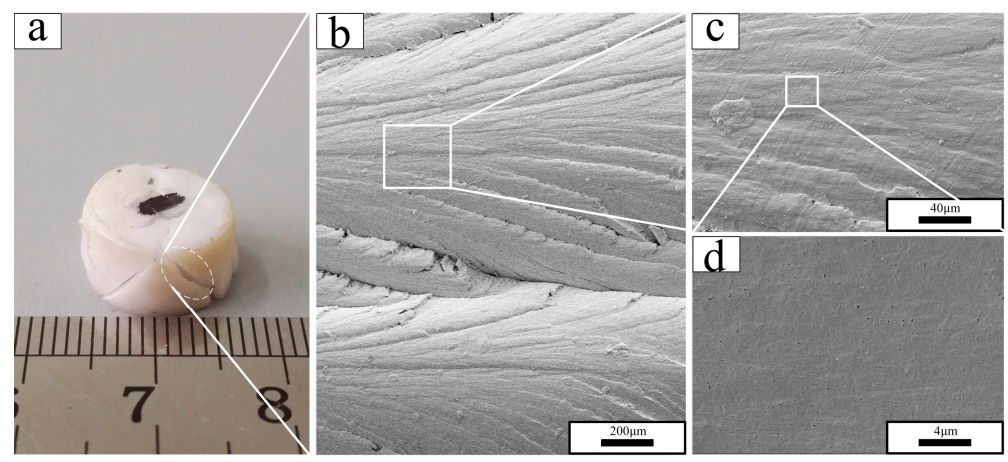

Figure 9. Recovered sample and fracture surface morphology under different magnifications of PTFE tested at $-18^{\circ} \mathrm{C}$ : (a) recovered PTFE sample; (b) magnification of 100; (c) magnification of 500; (d) magnification of 5000 .
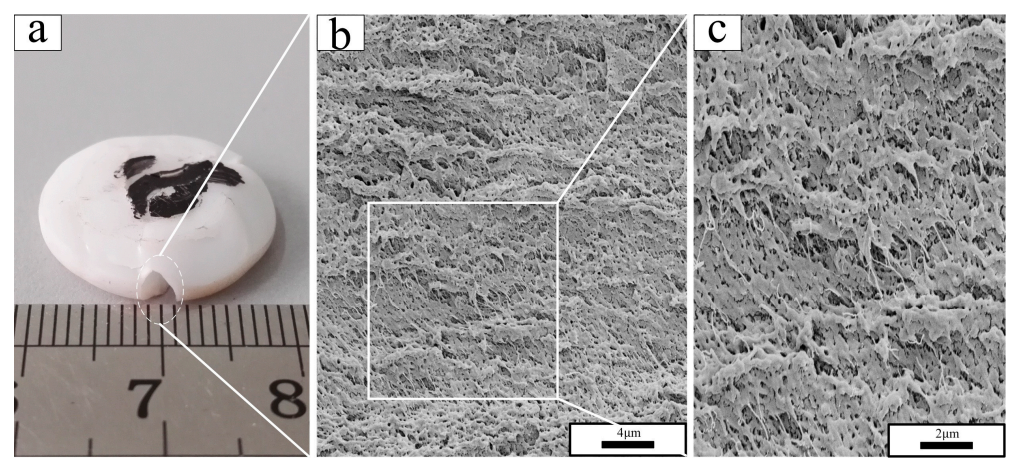

Figure 10. Recovered sample and fracture surface morphology under different magnifications of PTFE tested at $22{ }^{\circ} \mathrm{C}$ : (a) recovered PTFE sample; (b) magnification of 5000; (c) magnification of 10,000.
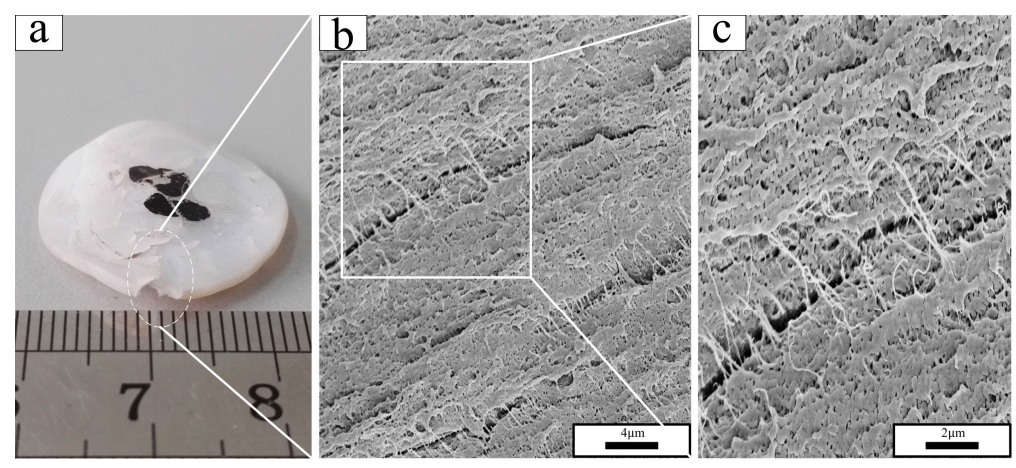

Figure 11. Recovered sample and fracture surface morphology under different magnifications of PTFE tested at $35^{\circ} \mathrm{C}$ : (a) recovered PTFE sample; (b) magnification of 5000; (c) magnification of 10,000.

The stability of drawing fibrils is primarily determined by temperature and crystalline phase with additional dependence on loading rate and microstructure anisotropy [27]. O'Leary and Geil [28] 
measured the structure of an individual fibril using electron diffraction. The result shows a large perfect, low molecular weight crystal. Kitamura et al. [29] thought the formation of fibrils is a process of unraveling of the crystalline domains to form an oriented ribbon-like crystalline structure in the direction of loading. Ariawan et al. [30] also suggested that fibrils are oriented amorphous PTFE formed by the unwinding of the crystalline domains, while Brown and Dattelbaum [27] proposed that PTFE fibrils nucleate from a point of stress concentration. Although the formation mechanism and precise structure of fibrils is still not clear, it is believed that the fibrils provide an additional resistance to crack propagation and enhance the ductility of the material. On the one hand, the formation of fibrils is an efficient mechanism to dissipate energy [31,32]; on the other hand, as the fibrils bride the crack surface, they can blunt the crack tip and slow down the propagation of crack [33,34].

\subsection{Reaction Phenomenon under Quasi-Static Compression}

Samples tested at $16{ }^{\circ} \mathrm{C}$ and below failed with shear crack and no reaction phenomenon was observed (Figure 12a-c), while all of the samples tested at $22{ }^{\circ} \mathrm{C}$ and above reacted completely and burned into a pile of black powder (Figure 12d), accompanied by bright flame and explosion sound.
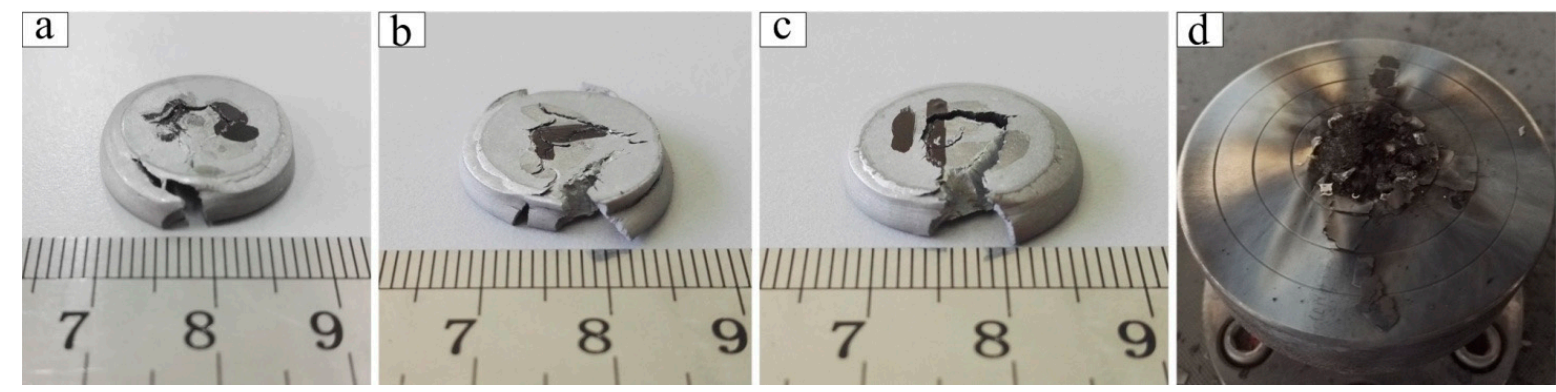

Figure 12. The recovered samples of Al-PTFE after quasi-static compression at different temperatures: (a) $-18{ }^{\circ} \mathrm{C}$; (b) $0^{\circ} \mathrm{C}$; (c) $16{ }^{\circ} \mathrm{C}$; (d) 22,35 , and $80{ }^{\circ} \mathrm{C}$.

The reaction process of Al-PTFE samples under quasi-static compression is shown in Figure 13. The reaction originated from the vicinity of the outer surface of the sample (Figure 13a) and the initiation was always accompanied by an opening crack (Figure 13b), which was formed by the transverse tensile stress during compression. Then the reaction spread throughout the sample rapidly (Figure 13c). The whole process lasted about $2360 \mathrm{~ms}$ (Figure 13d).
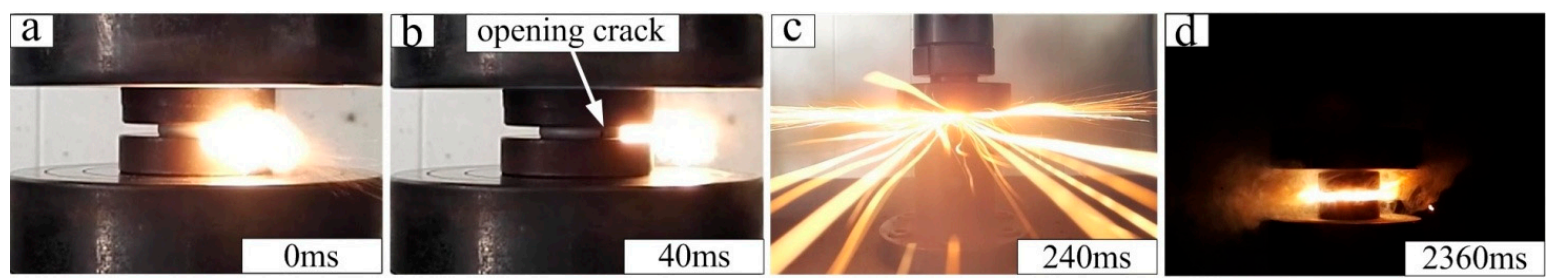

Figure 13. The reaction phenomenon of Al-PTFE samples under quasi-static compression: (a) first sign of initiation; (b) crack formed along with the initiation; (c) violent exothermic reaction; (d) the end of reaction.

Feng et al. [35] thought that the reaction phenomenon occurs due to the abrupt energy release along the opening crack in the Al-PTFE sample. The abrupt release of energy absorbed during deformation could cause the temperature to rise high enough to induce a chemical reaction between $\mathrm{Al}$ and PTFE at the opening crack tip. High temperatures at the crack tips of polymers which undergo catastrophic failure have been confirmed experimentally by instruments such as thermocouples, infrared detectors, and heat sensitive films [36-38]. The magnitude of the rise in temperature is 
determined by the amount of plastic work and the crack speed [36,37]. In brief, sufficient toughness (the ability of material to absorb energy during deformation, which could be obtained by calculating the area under the stress-strain curve) and an abrupt energy release are two decisive factors for the reaction of the Al-PTFE sample under quasi-static compression. As shown in Figure 14, due to the temperature-induced crystalline phase transformation of the PTFE matrix, the toughness of Al-PTFE showed a $10 \%$ increase, from $90.68 \mathrm{~J} / \mathrm{cm}^{3}$ at $16{ }^{\circ} \mathrm{C}$ (phase II) to $99.31 \mathrm{~J} / \mathrm{cm}^{3}$ at $22{ }^{\circ} \mathrm{C}$ (phase IV). Moreover, the true stress-strain curves of Al-PTFE samples at $22{ }^{\circ} \mathrm{C}$ and above (phases IV and I) showed no stress-drop phenomenon before failure (Figure 6), which indicated that the energy stored in the samples released instantaneously. Therefore, it is reasonable to speculate that Al-PTFE samples could react under quasi-static compression when subjected to temperatures above $19{ }^{\circ} \mathrm{C}$ (crystalline phase transition temperature of PTFE between phases II and IV).

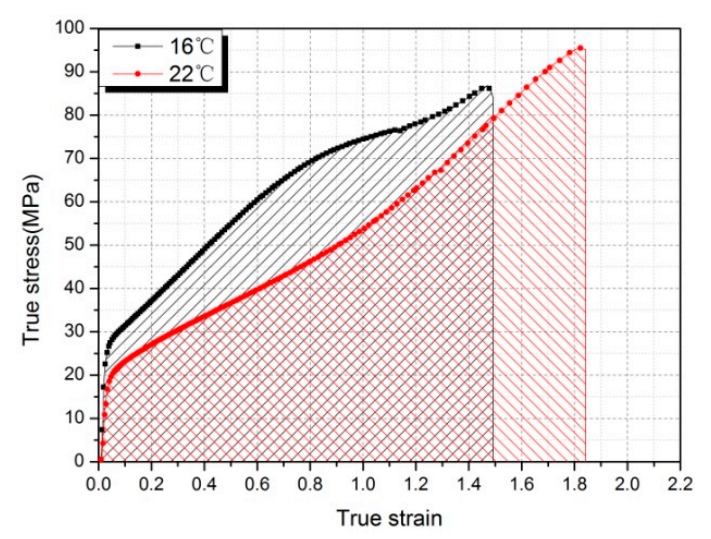

Figure 14. The toughness of Al-PTFE at 16 and $22^{\circ} \mathrm{C}$, respectively.

\section{Conclusions}

Quasi-static compression experiments were carried out to investigate the influence of temperature on the mechanical properties and reactive behavior of Al-PTFE. Tests were conducted over a range of temperatures from $-18{ }^{\circ} \mathrm{C}$ to $80^{\circ} \mathrm{C}$, capturing the three crystalline phases of the PTFE matrix with transitions at 19 and $30^{\circ} \mathrm{C}$. The following conclusions can be drawn from this study:

(1) The mechanical behavior of Al-PTFE is strongly temperature-dependent, and a transition from brittleness to ductility with increased temperature is observed. The yield stress, true failure strain, and flow stress exhibit an unusual change resulting from the temperature-induced crystalline phase transition of the PTFE matrix between phases II and IV.

(2) In the scanning electron micrographs, the PTFE matrix showed two different fracture mechanisms: brittle fracture with a smooth fracture surface in phase II (below $19^{\circ} \mathrm{C}$ ) and ductile fracture with the formation of PTFE fibrils on the rough fracture surface in phases IV and I (above $19^{\circ} \mathrm{C}$ ).

(3) This work demonstrates that although Al-PTFE has been considered inert under quasi-static compression, the reaction phenomenon in phases IV and I necessitates the consideration of safety during service at temperatures above $19^{\circ} \mathrm{C}$.

Acknowledgments: The financial support from the National Natural Science Foundation of China (General Program, Grant No. 51673213) is gratefully acknowledged. This paper was also sponsored by the China Scholarship Council.

Author Contributions: Huai-Xi Wang, Xiang Fang, and Yu-Chun Li conceived and designed the experiments; Huai-Xi Wang, Zhen-Ru Gao, and Shuang-Zhang Wu performed the experiments; Bin Feng analyzed the data; Huai-Xi Wang and Yu-Chun Li wrote the paper.

Conflicts of Interest: The authors declare no conflict of interest. 


\section{References}

1. Joshi, V.S. Process for Making Polytetrafluoroethylene-Aluminum Composite and Product Made. U.S. Patent US6,547,993 B1, 15 April 2003.

2. Dolgoborodov, A.Y.; Makhov, M.N.; Kolbanev, I.V.; Streletskiǔ, A.N.; Fortov, V.E. Detonation in an aluminum-Teflon mixture. JETP Lett. 2005, 81, 311-314. [CrossRef]

3. Raftenberg, M.N.; Mock, W., Jr.; Kirby, G.C. Modeling the Impact Deformation of Rods of a Pressed PTFE/Al Composite Mixture. Int. J. Impact Eng. 2008, 35, 1735-1744. [CrossRef]

4. Ge, C.; Dong, Y.X.; Maimaitituersun, W. Mircroscale simulation on mechanical properties of Al/PTFE composite based on real microstructures. Materials 2016, 9, 590. [CrossRef] [PubMed]

5. Cai, J.; Nesterenko, V.F.; Vecchio, K.S.; Jiang, F.; Herbold, E.B.; Benson, D.J.; Addiss, J.W.; Walley, S.M.; Proud, W.G. The influence of metallic particle size on the mechanical properties of polytetrafluoroethylene-Al-W powder composties. Appl. Phys. Lett. 2008, 92, 031903. [CrossRef]

6. Xu, S.L.; Yang, S.Q.; Zhang, W. The mechanical behaviors of polytetrafluoroethylene/Al/W energetic composites. J. Phys. Condens. Mater. 2009, 21, 285401. [CrossRef] [PubMed]

7. Zhang, X.F.; Zhang, J.; Qiao, L.; Shi, A.S.; Zhang, Y.G.; He, Y.; Guan, Z.W. Experimental study of the compression properties of $\mathrm{Al} / \mathrm{W} / \mathrm{PTFE}$ granular composites under elevated strain rates. Mater. Sci. Eng. A 2013, 581, 48-55. [CrossRef]

8. Wang, L.; Liu, J.X.; Li, S.K.; Zhang, X.B. Investigation on reaction energy, mechanical bebavior and impact insensitivity of W-PTFE-Al composites with different W percentage. Mater. Des. 2016, 92, 397-404. [CrossRef]

9. Ge, C.; Maimaitituersun, W.; Dong, Y.X.; Tian, C. A study on the mechanical properties and impact-induced initiation characteristics of brittle PTFE/Al/W reactive materials. Materials 2017, 10, 452. [CrossRef]

10. Feng, B.; Fang, X.; Li, Y.C.; Wang, H.X.; Mao, Y.M.; Wu, S.Z. An initiation phenomenon of Al-PTFE under quasi-static compression. Chem. Phys. Lett. 2015, 637, 38-41. [CrossRef]

11. Feng, B.; Li, Y.C.; Wu, S.Z.; Wang, H.X.; Tao, Z.M.; Fang, X. A crack-induced initiation mechanism of Al-PTFE under quasi-static compression and the investigation of influencing factors. Mater. Des. 2016, 108, 411-417. [CrossRef]

12. Koo, G.P.; Andrews, R.D. Mechanical behavior of Polytetrafluoroethylene around the room-temperature first-order transition. Polym. Eng. Sci. 1969, 9, 268-276. [CrossRef]

13. Bunn, C.W.; Howells, E.R. Structures of molecules and crystals of fluoro-carbons. Nature 1954, 174, 549-551. [CrossRef]

14. Mccrum, N.G. An internal friction study of polytetrafluoroethylene. J. Polym. Sci. 1959, 34, 355-369. [CrossRef]

15. Sperati, C.A.; Starkweather, H.W. Fluorine-containing polymers. II. Polytetrafluoroethylene. Adv. Polym. Sci. 1961, 2/4, 465-495. [CrossRef]

16. Brown, E.N.; Rae, P.J.; Gray, G.T. The influence of temperature and strain rate on the tensile and compressive constitutive response of four fluoropolymers. J. Phys. IV 2006, 134, 935-940. [CrossRef]

17. Wu, C.K.; Nicol, M. Reman spectra of high pressure phase and phase transition of polytetrafluoroethylene (Teflon). Chem. Phys. Lett. 1973, 21, 153-157. [CrossRef]

18. Clark, E.S. The molecular conformations of polytetrafluoroethylene: Forms II and IV. Polymer 1999, 40, 4659-4665. [CrossRef]

19. Bunn, C.W.; Cobbold, A.J.; Palmer, R.P. The fine structure of polytetrafluoroethylene. J. Polym. Sci. 1958, 28, 365-376. [CrossRef]

20. Weeks, J.J.; Sanchez, I.C.; Eby, R.K.; Poser, C.I. Order-disorder transitions in polytetrafluoroethylene. Polymer 1980, 21, 325-331. [CrossRef]

21. Cox, J.M.; Wright, B.A.; Wright, W.W. Thermal degradation of fluorine-containing polymers. Part I. Degradation in vacuum. J. Appl. Polym. Sci. 1964, 8, 2935-2950. [CrossRef]

22. Nielson, D.B.; Tanner, R.L.; Lund, G.K. High Strength Reactive Materials. U.S. Patent US20030096897 A1, 22 May 2003.

23. Speerschneider, C.J.; Li, C.H. A Correlation of Mechanical Properties and Microstructure of Polytetrafluoroethylene at Various Temperatures. J. Appl. Phys. 1963, 34, 3004-3007. [CrossRef]

24. Brown, E.N.; Rae, P.J.; Orler, E.B.; Gray, G.T., III; Dattelbaum, D.M. The effect of crystallinity on the fracture of polytetrafluoroethylene (PTFE). Mater. Sci. Eng. C 2006, 26, 1338-1343. [CrossRef] 
25. Rae, P.J.; Dattelbaum, D.M. The properties of poly(tetrafluoroethylene) (PTFE) in compression. Polymer 2004, 45, 7615-7625. [CrossRef]

26. Rae, P.J.; Brown, E.N. The properties of poly(tetrafluoroethylene) (PTFE) in tension. Polymer 2005, 46, 8128-8140. [CrossRef]

27. Brown, E.N.; Dattelbaum, D.M. The role of crystalline phase on fracture and microstructure evolution of polytetrafluoroethylene (PTFE). Polymer 2005, 46, 3056-3068. [CrossRef]

28. O'Leary, K.; Geil, P.H. Polytetrafluoroethylene fibril structure. J. Appl. Phys. 1967, 38, 4169-4181. [CrossRef]

29. Kitamura, T.; Okabe, S.; Tanigaki, M.; Kurumada, K.; Ohshima, M.; Zanazawa, S. Morphology change in polytetrafluoroethylene (PTFE), porous membrance caused by heat treatment. Polym. Eng. Sci. 2000, 40, 809-817. [CrossRef]

30. Ariawan, A.B.; Ebnesajjad, S.; Hatzikiriakos, S.G. Properties of polytetrafluoroethylene (PTFE) paste extrudates. Polym. Eng. Sci. 2002, 42, 1247-1259. [CrossRef]

31. Jie, M.; Tang, C.Y.; Li, Y.P.; Li, C.C. Damage evolution and energy dissipation of polymers with crazes. Theor. Appl. Fract. Mech. 1998, 28, 165-174. [CrossRef]

32. Aglan, H.; Gan, Y.; El-Hadeki, M.; Faughnan, P.; Bryan, C. Evaluation of fatigue fracture resistance of unfilled and filled polytetrafluoroethylene materials. J. Mater. Sci. 1999, 34, 83-97. [CrossRef]

33. Sun, B.N.; Hsiao, C.C. Nonlinear quasi-fracture behavior of polymers. J. Appl. Phys. 1985, 57, $170-174$. [CrossRef]

34. Marissen, R. Craze growth mechanics. Polymer 2000, 41, 1119-1129. [CrossRef]

35. Feng, B.; Li, Y.C.; Hao, H.; Wang, H.X.; Hao, Y.F.; Fang, X. A mechanism of hot-spots formation at the crack tip of Al-PTFE under quasi-static compression. Propellants Explos. Pyrotech. 2017, 42, 1-8. [CrossRef]

36. Fuller, K.N.G.; Fox, P.G.; Field, J.E. The temperature rise at the tip of fast-moving cracks in glassy polymers. Proc. R. Soc. A 1975, 341, 537-557. [CrossRef]

37. Swallowe, G.M.; Field, J.E.; Horn, L.A. Measurements of transient high temperatures during the deformation of polymers. J. Mater. Sci. 1986, 21, 4089-4096. [CrossRef]

38. Zhang, J.W.; Jiang, H.; Jiang, C.K.; Cheng, Q.; Kang, G.Z. In-situ observation of temperature rise during scratch testing of poly (methylmethacrylate) and polycarbonate. Tribol. Int. 2016, 95, 1-4. [CrossRef]

(C) 2018 by the authors. Licensee MDPI, Basel, Switzerland. This article is an open access article distributed under the terms and conditions of the Creative Commons Attribution (CC BY) license (http:/ / creativecommons.org/licenses/by/4.0/). 